\title{
STEROID-INDUCED DYSGLYCAEMIA DURING FIRST 48 HOURS OF STEROID THERAPY IN HOSPITALISED PATIENTS
}

\author{
Venkateswarlu Dhirisala', Hariharan Chellapandy², Sailendri Ganapathy ${ }^{3}$
}

${ }^{1}$ Associate Professor, Department of General Medicine, Government Kilpauk Medical College and Hospital, Chennai. ${ }^{2}$ Associate Professor, Department of General Medicine, Government Kilpauk Medical College and Hospital, Chennai. 3Junior Resident, Department of General Medicine, Government Kilpauk Medical College and Hospital, Chennai.

\begin{abstract}
BACKGROUND

Glucocorticoid (GC) is crucial for glucose, lipid and protein metabolism and therefore for energy balance. GCs are used in treatment of chronic obstructive pulmonary disease (COPD) exacerbations, a clinical manifestation of an acute-on-chronic inflammatory process in the airways, often with systemic spill over. In spite of their enormous useful actions, usage of corticosteroid is under limitation in view of its side effect profile, which in turn is dependent on amount of drug and duration for which the drug was administered for the sake of treatment. The combination of hypertension, central obesity and glucose intolerance is called as 'Reaven's Syndrome X' or the 'Metabolic Syndrome'. The most common adverse effect following steroid therapy is the development of (dys) hyperglycaemia. Avoidance of hypoglycaemia is important because it has been implicated as a potential cause of increased mortality in patients receiving intensive insulin therapy. A better understanding of the glycaemic effect of prednisolone will allow the development of a specific treatment strategy for prednisolone-induced hyperglycaemia that targets the time of day during which hyperglycaemia predominates.
\end{abstract}

\section{MATERIALS AND METHODS}

The study is a descriptive study.

Study Period- 6 months.

Study Area- Govt. Royapettah Hospital attached to Govt. Kilpauk Medical College.

\section{RESULTS}

In my study, it is found that there is rise in capillary blood glucose level after administration of steroid during all the three different times $(6,12$ \& 48 hours) and with respect to all the three different drugs given to the patient for their exacerbation. Thus the occurrence of hyperglycaemia within 48 hours in patients started on corticosteroid therapy is proven. The Capillary Blood Glucose level after administration of the drug is highest at 191.47 with Hydrocortisone $>162.47$ with Dexamethasone $>152.42$ with Prednisolone. So, the risk of (dys) hyperglycaemia is highest with Hydrocortisone (short acting) when compared with other two drugs (long acting). Thus, steroid-induced hyperglycaemia is more with parenteral steroids than oral forms. The Capillary Blood Glucose peaks at the $12^{\text {th }}$ hour after administration of any of the three drugs namely Dexamethasone, Hydrocortisone \& Prednisolone. $\mathrm{HbA}_{1 \mathrm{c}}$ \& Systolic BP has significant correlation for Dexamethasone. Systolic BP \& Waist Circumference has significant correlation for Hydrocortisone. $\mathrm{HbA}_{1 c} \&$ Waist Circumference has significant correlation for Prednisolone.

\section{CONCLUSION}

The short-acting steroid Hydrocortisone with highest rise in CBG at all three times after its administration is to be avoided unless the clinical condition demands. Oral Prednisolone is comparatively a safer drug with less side effect (hyperglycaemia) profile and ease of administration.

\section{KEYWORDS}

Metabolic Syndrome.

HOW TO CITE THIS ARTICLE: Dhirisala V, Chellapandy H, Ganapathy S. Steroid-induced dysglycaemia during first 48 hours of steroid therapy in hospitalised patients. J. Evolution Med. Dent. Sci. 2017;6(89):6253-6257, DOI: 10.14260/jemds/2017/1359

\section{BACKGROUND}

Glucocorticoids (GC) are produced by the adrenal cortex, under the direction of hypothalamic-pituitary-adrenal axis. They are crucial for glucose, lipid and protein metabolism and therefore for energy balance.(1)

'Financial or Other Competing Interest': None.

Submission 28-08-2017, Peer Review 30-10-2017,

Acceptance 07-11-2017, Published 13-11-2017.

Corresponding Author:

Venkateswarlu Dhirisala

New No. 10 /Old No. 14

Sripuram 2nd Street,

Royapettah,

Chennai-14.

E-mail:balams82@gmail.com

DOI: $10.14260 /$ jemds $/ 2017 / 1359$

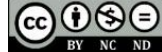

At supraphysiological concentrations, i.e. $>10 \mathrm{mg} /$ day as that is their normal daily rate of secretion, GCs will exhibit their anti-inflammatory action and so used for treating a wide array of inflammatory and (AI) autoimmune conditions.(2) Side effects of steroids are mainly metabolic derangements, including the development of central adiposity, hepatic steatosis, dyslipidaemia characterised by increased plasma levels of triglyceride rich lipoproteins (TRL) and nonesterified fatty acids (NEFA), increased breakdown of skeletal muscle mass, insulin resistance, glucose intolerance and overt diabetes in susceptible individuals.(3)

The most common adverse effect following steroid therapy is the development of (dys) hyperglycaemia.(4) Hyperglycaemia is an independent predictor of increased mortality in hospitalised patients with a range of 
comorbidities, including an exacerbation of COPD. By opposing the actions of insulin, glucocorticoids could contribute to insulin resistance and its association with other cardiovascular risk factors. ${ }^{(5)}$

Studies showed that the glycaemic rise related to steroid therapy usually begins 4 hours after the dose and usually persists for up to 16 hours. Therefore, conventional testing methods to diagnose diabetes may not be appropriate in steroid-induced diabetes.(6) Fasting hyperglycaemia may not be evident in many cases and only postprandial hyperglycaemia is seen in most patients. So it is hypothesised that prednisolone causes substantial hyperglycaemia, predominantly in the postprandial period. A better understanding of the glycaemic effect of prednisolone will allow the development of a specific treatment strategy for prednisolone-induced hyperglycaemia that targets the time of day during which hyperglycaemia predominates.

\section{Aims and Objectives}

1. To study the occurrence of hyperglycaemia within 48 hours in patients started on corticosteroid therapy.

2. To study the various factors associated with steroidinduced hyperglycaemia with special reference to the-

a) Nature of corticosteroid used.

b) Presence of risk factors for diabetes.

\section{MATERIALS AND METHODS}

\section{Study Design}

Descriptive study.

\section{Study Period}

6 months.

\section{Study Area}

Govt. Royapettah Hospital attached to Govt. Kilpauk Medical College, Chennai.

\section{Study Population}

Known Bronchial Asthma or Chronic Obstructive Pulmonary Disease patient aged $\geq 18$ years, non-diabetic, on oral drugs like salbutamol and theophylline and not on any oral/inhalational steroid so far and not received any parenteral steroid in last 4 weeks, admitted for acute exacerbation but not in respiratory failure who are to be initiated on steroid therapy at Govt. Royapettah Hospital attached to Govt. Kilpauk Medical College, Chennai.

\section{Sample Size}

Estimated prevalence of steroid-induced hyperglycaemia is $65 \%$

With a precision of 10

$$
\text { Sample size is } 1.96 \times 1.96 \times 65 \times 35=87
$$$$
10 \times 10
$$

With a $10 \%$ margin, Sample size $=100$.

\section{Inclusion Criteria}

Known Bronchial Asthma or Chronic Obstructive Pulmonary Disease patient aged $\geq 18$ years, non-diabetic, on oral drugs like salbutamol and theophylline and not on any oral/inhalational steroid so far and not received any parenteral steroid in last 4 weeks, admitted for acute exacerbation but not in respiratory failure who are to be initiated on steroid therapy.

\section{Exclusion Criteria}

- Known diabetic.

- $\quad$ RBS 140-199 mg/dL with $\mathrm{HbA}_{1 \mathrm{c}} \geq 6.5$.

- Patient who received parenteral steroids in last 4 weeks.

- $\quad$ Patient on IV drip containing dextrose.

- Patient in respiratory failure on mechanical ventilation/moribund state in need of IV fluid containing dextrose.

- Patient on oral steroid (e.g. Very severe persistent asthma patient on oral corticosteroid treatment).

- Pregnant or lactating female.

- $\quad$ Age $<18$ years.

\section{Case Definition}

Known Bronchial Asthma or Chronic Obstructive Pulmonary Disease patient aged $\geq 18$ years, non-diabetic, on oral drugs like salbutamol and theophylline and not on any oral/inhalational steroid so far and not received any parenteral steroid in last 4 weeks, admitted for acute exacerbation but not in respiratory failure (signs include cyanosis, altered mental status with $\mathrm{SpO} 2<$ 90 , heart rate $<60 /$ minute, systolic blood pressure $<90 \mathrm{mmHg}$ ) are taken as cases.

\section{Methodology}

Known Bronchial Asthma or Chronic Obstructive Pulmonary Disease patient aged $\geq 18$ years, non-diabetic, on oral drugs like salbutamol and theophylline and not on any oral/inhalational steroid so far and not received any parenteral steroid in last 4 weeks, admitted for acute exacerbation but not in respiratory failure are taken into the study.

Patients to be initiated on steroid therapy: parenteralhydrocortisone/dexamethasone or oral- prednisolone in standard doses as demanded by the clinical setting. So patients will be substratified depending on the type and dose of steroid used.

Doses of Steroids used in the study are Injection Hydrocortisone - $100 \mathrm{mg} 8^{\text {th }}$ hourly, Injection Dexamethasone $-4 \mathrm{mg} 12^{\text {th }}$ hourly, Tablet Prednisolone $5 \mathrm{mg}$ -4 tablets $12^{\text {th }}$ hourly.

Capillary blood glucose (CBG) level of each patient at the time of admission (pre-therapy) will be checked with the help of glucometer (Accu-Chek active).

$2 \mathrm{~mL}$ of blood will be collected from each patient at the time of admission (pre-therapy) and sent for $\mathrm{HbA}_{1 \mathrm{c}}$.

Again, CBG level of each patient at 6, 12, 48 hours after initiation of steroid therapy is checked and noted.

$2 \mathrm{~mL}$ of blood for doing fasting lipid profile will also be sent to biochemistry lab, Govt. Royapettah Hospital for processing.

\section{Outcomes to be Studied}

Incidence of steroid-induced hyperglycaemia ( $C B G \geq 200$ ); is Parenteral corticosteroid having more propensity to cause hyperglycaemia than oral corticosteroid?

The time period at which hyperglycaemia is more common after the administration of steroid (so that antihyperglycaemic drugs can be targeted at the right time as 
hyperglycaemia is an independent cardiovascular risk factor). Association between risk factors like obesity, dyslipidaemia, hypertension and steroid-induced hyperglycaemia.

\section{Statistical Methods}

Data was analysed using SPSS software version 16. Data was entered in MS Excel spreadsheet. The collected data were analysed by using Chi square test and student's t-test. Correlation between variables was done using Pearson correlation test. The qualitative data were expressed as numbers (\%), the quantitative data as mean \pm standard deviation (SD).

\section{RESULTS}

The sample size in our study is 100 patients. These patients fell into either one of the two classes which are bronchial asthma and chronic obstructive pulmonary disease. All the patients met with our inclusion criteria. They were administered one among the following three steroids namely Hydrocortisone, Dexamethasone \& Prednisolone for their acute exacerbation.

- $\quad$ Dose of Hydrocortisone being 100 mg IV t.d.s.

- Dose of Dexamethasone being $4 \mathrm{mg}$ IV b.d.

- Dose of Prednisolone being 5 mg 4-0 - 4 (oral).

We have concluded the following

\begin{tabular}{|c|c|c|c|c|c|}
\hline \multicolumn{6}{|c|}{ Steroid Used (dhp) * SEX Cross tabulation } \\
\hline & & & \multicolumn{2}{|c|}{ SEX } & \multirow{2}{*}{ Total } \\
\hline & & & $\mathbf{F}$ & $\mathbf{M}$ & \\
\hline \multirow{6}{*}{$\begin{array}{c}\text { Steroid } \\
\text { used (dhp) }\end{array}$} & \multirow[b]{2}{*}{ D } & Count & 9 & 29 & 38 \\
\hline & & $\begin{array}{l}\text { \% within steroid } \\
\text { used (dhp) }\end{array}$ & $23.7 \%$ & $76.3 \%$ & $100.0 \%$ \\
\hline & \multirow[b]{2}{*}{$\mathrm{H}$} & Count & 13 & 25 & 38 \\
\hline & & $\begin{array}{c}\% \text { within steroid } \\
\text { used (dhp) }\end{array}$ & $34.2 \%$ & $65.8 \%$ & $100.0 \%$ \\
\hline & \multirow[b]{2}{*}{$P$} & Count & 11 & 13 & 24 \\
\hline & & $\begin{array}{c}\text { \% within steroid } \\
\text { used (dhp) }\end{array}$ & $45.8 \%$ & $54.2 \%$ & $100.0 \%$ \\
\hline \multirow{2}{*}{\multicolumn{2}{|c|}{ Total }} & Count & 33 & 67 & 100 \\
\hline & & $\begin{array}{l}\% \text { within steroid } \\
\text { used (dhp) }\end{array}$ & $33.0 \%$ & $67.0 \%$ & $100.0 \%$ \\
\hline \multicolumn{6}{|c|}{$\begin{array}{c}\text { Table 1. Number of Patients Allotted to Each Drug } \\
\text { Category }\end{array}$} \\
\hline
\end{tabular}

Out of 100 patients in our study-

- $38 \%$ were given Hydrocortisone,

- $38 \%$ were given Dexamethasone and

- $\quad 24 \%$ were given Prednisolone.

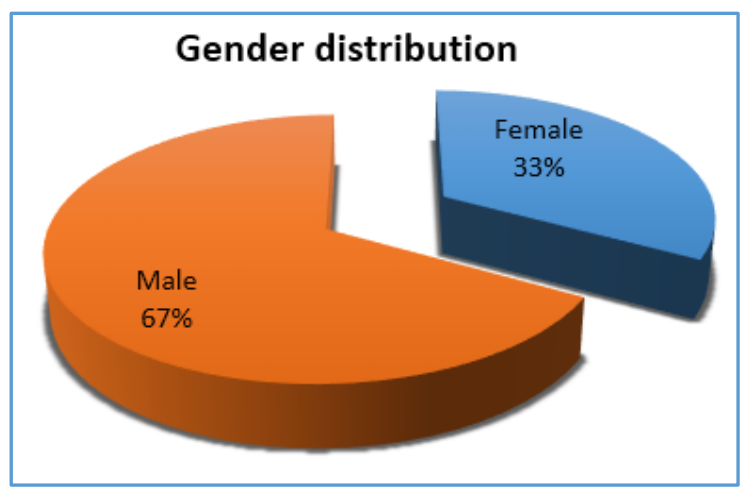

Figure 1. Gender in Each Drug



\begin{tabular}{|c|c|c|c|c|c|}
\hline & N & Minimum & Maximum & Mean & $\begin{array}{c}\text { St. } \\
\text { Deviation }\end{array}$ \\
\hline Age & 100 & 35 & 69 & 52.85 & 7.795 \\
\hline \multicolumn{5}{|c|}{ Table 2. Age Distribution } \\
\hline
\end{tabular}

\begin{tabular}{|c|c|c|c|}
\hline \multicolumn{5}{|c|}{ AGE } \\
\hline & $\mathbf{N}$ & Mean & Std. Deviation \\
\hline $\mathrm{D}$ & 38 & 52.89 & 7.904 \\
\hline $\mathrm{H}$ & 38 & 52.84 & 7.896 \\
\hline $\mathrm{P}$ & 24 & 52.79 & 7.791 \\
\hline Total & $\mathbf{1 0 0}$ & $\mathbf{5 2 . 8 5}$ & $\mathbf{7 . 7 9 5}$ \\
\hline
\end{tabular}

Drugs and their effect on CBG (Capillary Blood Glucose) Sub-categorical reports

\begin{tabular}{|c|c|c|c|}
\hline & Mean & Std. Deviation & N \\
\hline CBG at Admission & 105.24 & 5.410 & 38 \\
\hline CBG 6 hrs. & 141.11 & 22.576 & 38 \\
\hline CBG 12 hrs. & 162.47 & 30.642 & 38 \\
\hline CBG 48 hrs. & 137.95 & 22.262 & 38 \\
\hline \multicolumn{2}{|c|}{ Table 3a. Steroid Used = D (Dexamethasone) } \\
\hline
\end{tabular}

\begin{tabular}{|c|c|c|c|}
\hline & Mean & Std. Deviation & N \\
\hline CBG at Admission & 105.13 & 8.011 & 38 \\
\hline CBG 6 hrs. & 163.34 & 20.690 & 38 \\
\hline CBG 12 hrs. & 191.47 & 22.299 & 38 \\
\hline CBG 48 hrs. & 159.71 & 20.701 & 38 \\
\hline \multicolumn{3}{|l}{ Table 3b. Steroid Used $=\mathbf{H}$ (Hdrocortisone) } \\
\hline
\end{tabular}

\begin{tabular}{|c|c|c|c|}
\hline & Mean & Std. Deviation & N \\
\hline CBG at Admission & 103.33 & 5.362 & 24 \\
\hline CBG 6 hrs. & 134.46 & 21.875 & 24 \\
\hline CBG 12 hrs. & 152.42 & 31.661 & 24 \\
\hline CBG 48 hrs. & 131.21 & 21.405 & 24 \\
\hline \multicolumn{3}{|c|}{ Table 3c. Steroid Used $=\boldsymbol{P ( P r e d n i s o l o n e )}$} \\
\hline
\end{tabular}

Time at which CBG Peaks with respect to Drug Administration



Figure 2a. CBG at Baseline 


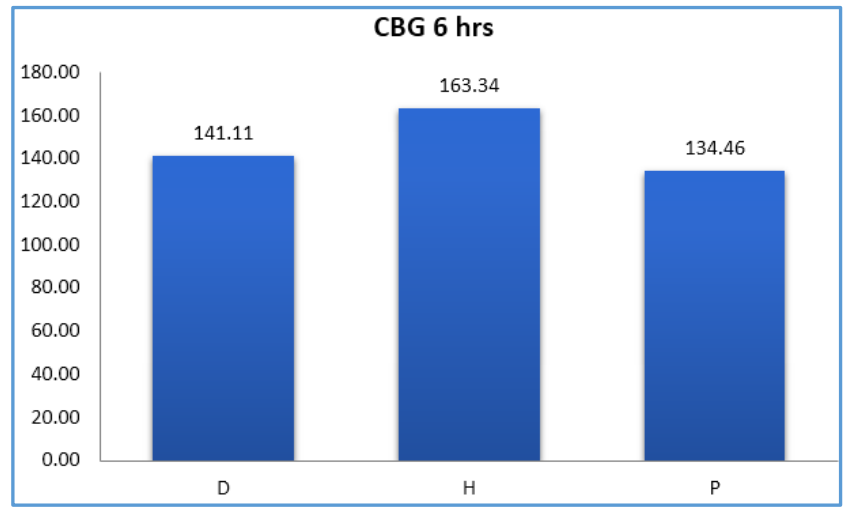

Figure 2b. CBG at $6^{\text {th }}$ Hour

Figure 2c. CBG at 12 ${ }^{\text {th }}$ Hour

\begin{tabular}{|c|c|}
\hline & CBG 12 hrs. \\
\hline D & 162.47 \\
\hline H & 191.47 \\
\hline P & 152.42 \\
\hline
\end{tabular}

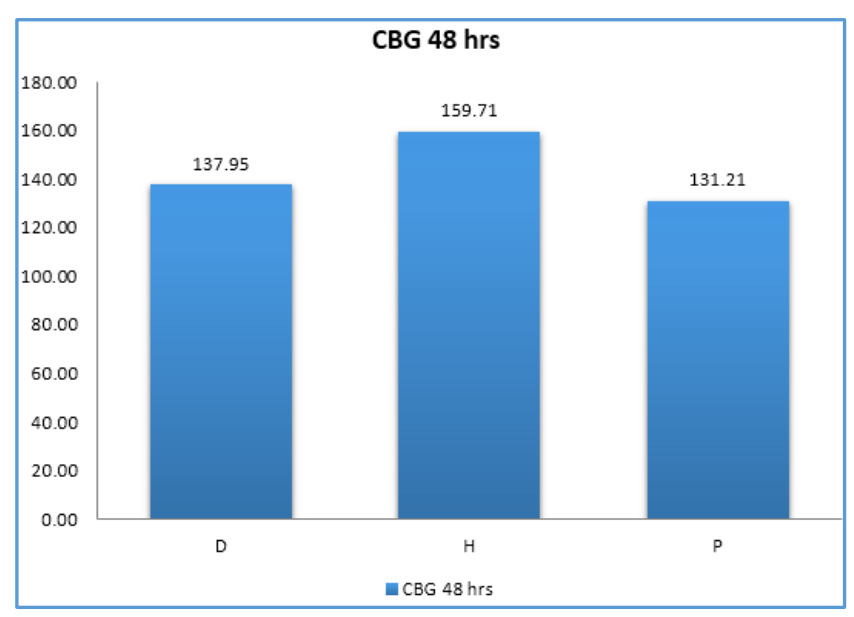

Figure 2d. CBG at $48^{\text {th }}$ Hour

\section{Risk Factors for Steroid-induced hyperglycaemia}

- Age

- BMI

- Waist Circumference

- Blood Pressure

- $\quad$ Fasting Lipid Profile (serum cholesterol \& triglyceride)

- Baseline $\mathrm{HbA}_{1 \mathrm{c}}$

\section{DISCUSSION}

Corticosteroid plays a significant role in our day-to-day practice. The aim of this work is to understand in depth about the most common adverse effect of corticosteroid which is hyperglycaemia. As hyperglycaemia is one among the most important factors that increases cardiovascular risk, this study is taken up to mitigate the risk.

\section{Through this study the following points have become} evident

1. There is rise in capillary blood glucose level after administration of steroids during all the three different times $(6,12 \& 48$ hours) and with respect to all the three different drugs given to the patient for their exacerbation. Thus, the occurrence of hyperglycaemia within 48 hours in patients started on corticosteroid therapy is proven.

2. The Capillary Blood Glucose level after administration of the drug is highest at 191.47 with Hydrocortisone > 162.47 with Dexamethasone $>152.42$ with Prednisolone.

3. So, the risk of (dys) hyperglycaemia is highest with Hydrocortisone (short acting) when compared with other two drugs (long acting).

4. Thus steroid-induced hyperglycaemia is more with parenteral steroids than oral forms.

5. The Capillary Blood Glucose peaks at the $12^{\text {th }}$ hour after administration of any of the three drugs namely Dexamethasone, Hydrocortisone \& Prednisolone.

Thus, traditional way of testing for fasting and postprandial blood sugar to see for dysglycaemia is no longer useful in case of steroid-induced hyperglycaemia. Many a times it has been told in other studies that it is the postprandial hyperglycaemia that predominates than the fasting hyperglycaemia in case of steroid-induced hyperglycaemia.

In my study, there are 6 different risk factors that have been taken and analysed especially with the hyperglycaemia that has occurred at $12^{\text {th }}$ hour of administration of any of the three corticosteroids.

\section{In my Study, it is found that-}

1. $\mathrm{HbA}_{1 \mathrm{c}} \&$ Systolic $\mathrm{BP}$ has significant correlation for Dexamethasone.

2. Systolic BP \& Waist Circumference has significant correlation for Hydrocortisone.

3. $\mathrm{HbA}_{1 \mathrm{c}} \&$ Waist Circumference has significant correlation for Prednisolone.

\section{CONCLUSION}

Similar to the other studies which show that the glycaemic rise related to steroid therapy usually begins 4 hours after the dose and usually persists, also CBG level starts rising at $6^{\text {th }}$ hour, peaks at $12^{\text {th }}$ hour $\&$ starts to 16 hours, declines by $48^{\text {th }}$ hour after administration of steroid therapy in my study.

Thus, a better understanding of the glycaemic effect of various steroids will allow the development of a specific treatment strategy for steroid-induced hyperglycaemia that targets the time of day during which hyperglycaemia predominates.

Current conventional strategies in treating hyperglycaemia may inadequately treat postprandial hyperglycaemia that occurs after steroid therapy, and use of long-acting basal insulin may precipitate nocturnal hypoglycaemia. So the short-acting steroid, Hydrocortisone with highest rise in CBG at all three times after its administration is to be avoided unless the clinical condition demands. Oral Prednisolone is comparatively a safer drug with less side effect (hyperglycaemia) profile \& ease of administration. But oral route not useful in patients not able to tolerate oral drugs due to vomiting and especially at acute exacerbations. It is also evident that increased waist circumference, BMI, baseline $\mathrm{HbA}_{1 c}$, blood pressure are all associated significantly with steroid-induced hyperglycaemia. 


\section{REFERENCES}

[1] Panza JA, Casino PR, Kilcoyne CM, et al. Impaired endothelium-dependent vasodilation in patients with essential hypertension: evidence that the abnormality is not at the muscarinic receptor level. J Am Coll Cardiol 1994;23(7):1610-6.

[2] Dunaif A, Scott D, Finegood D, et al. The insulinsensitising agent troglitazone improves metabolic and reproductive abnormalities in the polycystic ovary syndrome. J Clin Endocrinol Metab 1996;81(9):3299-306.

[3] Baynes KC, Whitehead J, Krook A, et al. Molecular mechanisms of inherited insulin resistance. QJM 1997;90(9):557-62.
[4] Fery F. Role of hepatic glucose production and glucose uptake in the pathogenesis of fasting hyperglycaemia in type 2 diabetes: normalization of glucose kinetics by short-term fasting. J Clin Endocrinol Metab 1994;78(3):536-42.

[5] Ferrannini E, Natali A, Capaldo B, et al. Insulin resistance, hyperinsulinemia, and blood pressure: role of age and obesity. European group for the study of insulin resistance (EGIR). Hypertension 1997;30(5):1144-9.

[6] Kahn CR, Goldfine ID, Neville DM, et al. Alterations in insulin binding induced by changes in vivo in the levels of glucocorticoids and growth hormone. Endocrinology 1978;103(4):1054-66. 